\title{
Cardiac Intensive Care Unit Admissions during COVID-19 Pandemic-A Single Center Experience
}

\author{
Radhapriya Yalamanchi ${ }^{1}$, Bipin Chandra Dasari ${ }^{2}$, Lavanya Narra ${ }^{3}$, Abraham Oomman $^{4}$, Pramod Kumar ${ }^{5}$, Rajeshwari Nayak ${ }^{6}$
} Refai Showkathali $^{7}$

\begin{abstract}
Aim: The impact of coronavirus disease 2019 (COVID-19) lockdown on cardiac emergency admissions to hospitals has been reported previously. We aimed to study the emergency room (ER) admissions to cardiac intensive care unit (CICU) at a tertiary care center during that period and compare this with admissions during the same time frame in the previous years.

Materials and methods: This is a retrospective observational study of patients admitted to the CICU during the pandemic period from March 22 to August 1 (inclusive) of 2020 and compared this with CICU admissions in the same time frame in the previous 2 years (2018 and 2019 ).

Results: During the study period in 2020, a total of 216 patients (age $59 \pm 14$ years) were admitted via ER, which is a $33 \%$ and $30 \%$ decline in admissions compared to $2019(n=322$, age $63 \pm 12$ years) and $2018(n=307$, age $62 \pm 13)$, respectively. The decline in admissions with the primary diagnosis of acute coronary syndrome (ACS), acute decompensated heart failure, arrhythmia, and other diagnoses during the study period in 2020 were $27 \%, 38 \%, 62 \%$, and 59\%, respectively, while there was a $50 \%$ increase in acute pulmonary embolism admission compared to the mean admission in 2018 and 2019. Weekly admission rates gradually increased from less than 10 per week in the first 3 weeks to $>15$ by eighth week of the study period in 2020, while the trend was same throughout the study period in the previous 2 years. The CICU mortality rate in 2020 study period was $4.6 \%$ compared to $3.9 \%$ in $2018(p=0.83)$ and $5.6 \%$ in $2019(p=0.70)$. The in-hospital mortality of these patients was also similar in all 3 years $(6.5 \%, 7.8 \%$, and $7.9 \%$ in 2018,2019 , and 2020 , respectively; $p=0.61)$.

Conclusion: Our study showed that CICU admissions during COVID-19 lockdown had declined compared to the previous years in a large tertiary center in India. Government and health organizations should educate the public early on during the pandemic about the consequences of ignoring other acute medical problems such as ACS, provide various measures for them to reach hospital early, and give reassurance with the best practices adopted in hospitals to avoid contracting the virus from the hospital environment.

Keywords: Acute coronary syndrome, Acute decompensated heart failure, Admissions, Cardiac emergency, Cardiac intensive care unit, COVID-19, Lockdown, Pandemic, Pulmonary embolism.

Indian Journal of Critical Care Medicine (2020): 10.5005/jp-journals-10071-23660
\end{abstract}

\section{INTRODUCTION}

Coronavirus disease 2019 (COVID-19) was declared as a pandemic by the World Health Organization on March 11, 2020. ${ }^{1}$ Further to this, most countries around the world imposed strict lockdown measures to contain the transmission of the virus at different time frames. The Indian government announced the first lockdown starting from March 24 for a period of 21 days, which subsequently got extended to different time frames in different states.

Cardiovascular involvement of COVID-19 can range from acute coronary syndrome (ACS), acute myocardial injury without obstructive coronary artery disease (myocarditis, stress cardiomyopathy), arrhythmias, heart failure, cardiogenic shock, pericardial effusion, and various thromboembolic complications. ${ }^{2}$ Cardiac societies such as the American College of Cardiology and Cardiological Society of India released guidelines about the management of patients with cardiovascular disease and myocardial infarction during COVID-19 in April 2020. These guidelines addressed the concerns about the safety of healthcare workers without compromising the best delivery of care to the patient. ${ }^{3,4}$ Reports of several studies from various countries were published showing significant reduction in admission of patients with cardiac emergency to hospital during this period of lockdown. ${ }^{5-14}$

We aimed to study the emergency room (ER) admissions to cardiac intensive care unit $(\mathrm{CICU})$ at a tertiary care center during
${ }^{1-7}$ Department of Cardiology, Apollo Main Hospital, Chennai, Tamil Nadu, India

Corresponding Author: Refai Showkathali, Department of Cardiology, Apollo Main Hospital, Chennai, Tamil Nadu, India, Phone: +91-4428296150, e-mail: refais@gmail.com

How to cite this article: Yalamanchi R, Dasari BC, Narra L, Oomman A, Kumar P, Nayak R, et al. Cardiac Intensive Care Unit Admissions during COVID-19 Pandemic-A Single Center Experience. Indian J Crit Care Med 2020;24(11):1103-1105.

Source of support: Nil

Conflict of interest: None

this period of lockdown and compared with admissions during the same period in the previous years.

\section{Materials and Methods}

This is a retrospective observational study of patients getting admitted to the CICU during the COVID-19 pandemic period from March 22 to August 1 (inclusive) of 2020 to our institute. Information about the $\mathrm{CICU}$ admissions during the same period of the previous 2 years (2018 and 2019) were also collected. The data were obtained from our electronic database and medical 
records of patients. All procedures followed were in accordance with the ethical standards of the responsible committee on human experimentation (institutional and national) and with the Helsinki Declaration of 1975, as revised in 2000.

We analyzed the patient records to identify the primary diagnosis and divided them to identify if there was change in admission rates with different diagnoses. Standard definition is used for ACS, which includes ST-elevation myocardial infarction (STEMI), non-ST elevation myocardial infarction, and unstable angina. Acute decompensated heart failure (ADHF) included patients with valvular heart disease, cardiomyopathy (ischemic or nonischemic), or arrhythmia presenting with signs of heart failure. Patients were included in the arrhythmia group if they had brady- or tachy-arrhythmia, but without signs of heart failure. Apart from the above definitions and acute pulmonary embolism (PE), all patients admitted to CICU via ER were included in the "Other diagnoses" group (e.g., hypertensive emergencies, metabolic abnormalities, etc.).

\section{Results}

During the study period in 2020, a total of 216 patients (age $59 \pm$ 14 years) were admitted via ER, which is a $33 \%$ and $30 \%$ decline in admissions compared to 2019 ( $n=322$, age $63 \pm 12$ years) and 2018 ( $n=307$, age $62 \pm 13$ years), respectively. The comparative admissions with the primary diagnosis of ACS, ADHF, arrhythmia, acute $P E$, and others are shown in Figure 1. The decline in admissions with the primary diagnosis of ACS, ADHF, arrhythmia, and other diagnoses during the study period in 2020 were $27 \%, 38 \%, 62 \%$, and $59 \%$, respectively, while there was a $50 \%$ increase in acute PE admission compared to the mean admission in 2018 and 2019. On plotting the weekly admission rates during the 15 week period, it was noted that the admission rates gradually increased from less than 10 per week in the first 3 weeks to $>15$ by eighth week of the study period in 2020, while the trend was same throughout the study period in the previous 2 years (Fig. 2).

In those patients who presented with STEMI during the study period in 2020, fibrinolytic therapy (FT) was given to six patients compared to one in 2019 ( $11.8 \%$ vs $1 \%, p=0.006)$. All these six patients had symptoms suspicious of COVID-19 and were admitted

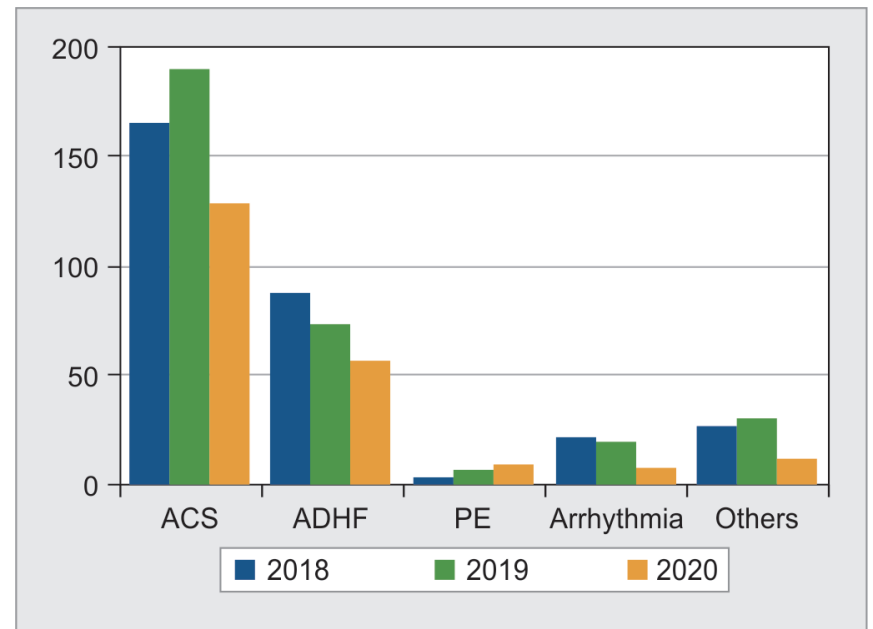

Fig. 1: Comparison of cardiac intensive care unit (CICU) admissions with different primary diagnosis during the study period in 2018, 2019, and 2020. ACS, acute coronary syndrome; ADHF, acute decompensated heart failure; $\mathrm{PE}$, pulmonary embolism during the early part of the study period (first 2 weeks). Emergency coronary angiography rate $(88.2 \%$ vs $99 \%, p=0.006)$ in STEMI was lower this year, but there was similar rate of primary percutaneous coronary intervention (PPCl) $(93.3 \%$ vs $89 \%, p=0.6)$ compared to 2020.

The CICU mortality rate in 2020 study period was $4.6 \%$ compared to $3.9 \%$ in $2018(p=0.83)$ and $5.6 \%$ in $2019(p=0.70)$. The in-hospital mortality of these patients was also similar in all 3 years $(6.5 \%, 7.8 \%$, and $7.9 \%$ in 2018,2019 , and 2020 , respectively, $p=0.61)$.

The COVID-19 reverse-transcription polymerase chain reaction was found to be positive in 15 patients (6.9\%) while in $\mathrm{CICU}$, out of which 4 died (26.7\%).

\section{Discussion}

We believe this is the first report from India addressing the issue of $\mathrm{CICU}$ admissions via ER during this pandemic period, even though there were multiple reports about the decline in ACS admissions and catheterization procedures from various countries during this COVID-19 pandemic. ${ }^{5-14}$

Our study showed that there was a gradual increase in admissions after the first 3 week period of lockdown. Patients were more reluctant to seek medical attention during the initial pandemic period as there was a panic mode among the public. This was mostly done by both mainstream and social media with information about COVID-19 projected throughout the day. However, as days went by, patients and their relatives were little more confident to come to hospital to get medical attention for non-COVID-19 medical conditions. This could also be partly due to patients not being able to tolerate their symptoms and ended up coming to hospital to seek medical help.

Even though our hospital caters for 24/7 PPCl to patients with STEMI, during this lockdown period unusually high number of patients underwent FT (six patients). There are few explanations for this: firstly, during the initial 2 weeks of the study period, interventional cardiologists were reluctant to do $\mathrm{PPCl}$ in those patients who had suspicious symptoms of COVID-19 along with history of travel abroad within the prior few weeks. All the six patients who underwent fibrinolysis fulfilled these criteria during the initial triage in emergency department. Therefore, as per the consensus from the cardiac societies, they were given FT in our institute to avoid delay in reperfusion. There were also several concerns about the availability and the quality of personal protective equipment (PPE) during the initial pandemic period. The technique of donning and doffing of PPE by cardiac catheter laboratory staff was also not optimal. Once the staffs were trained with appropriate doffing and donning techniques within the initial 2 weeks, clinicians were able to undertake PPCI even in COVID19 suspect patients with the necessary precautions, as per the guidelines.

There were several hypotheses been postulated to explain the decline in admissions for cardiac emergencies during this pandemic. ${ }^{15}$ The main factor is due to the fear of exposure and contracting the virus from an already infected patient in the hospital setup where most COVID-19 patients (symptomatic and asymptomatic) were treated in the initial pandemic period. Apart from these factors discussed earlier, in India, there are other unique factors that would have led to the reduction in emergency cardiac care unit admissions. Nearly half the patients in India with acute medical illness relies on their own transport to reach the hospital in 


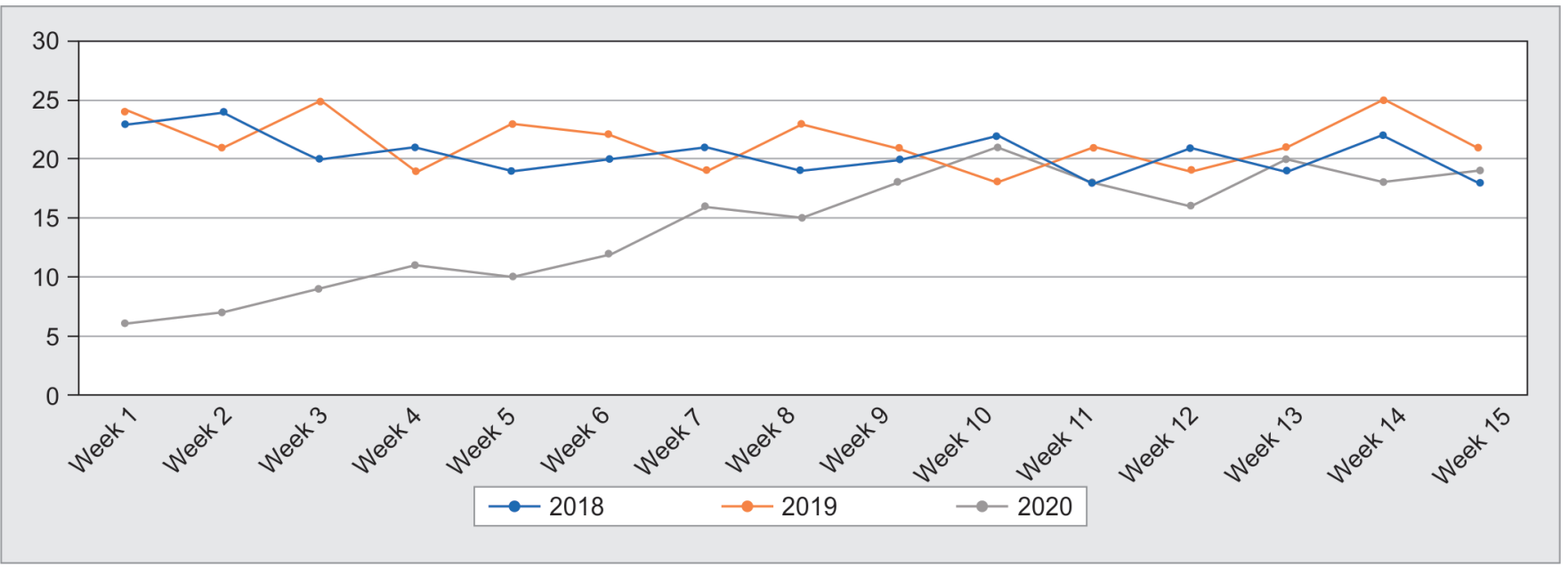

Fig. 2: Weekly trend of cardiac intensive care unit (CICU) admissions during the study period in 2018, 2019, and 2020

an emergency, as ambulance services are not as par to the western countries. Travelling in their own vehicle during the first few weeks of strict lockdown with frequent vehicle checks being undertaken all over the country must have also contributed to the decline in emergency admissions. Comparatively, even the ambulance services during the initial lockdown period were also much less and would have had a major impact on hospital admissions.

\section{Conclusion}

Our study from a large tertiary cardiac unit in South India showed that admissions to CICU was significantly reduced during COVID19 pandemic. Government and health organizations should educate the public (and also the healthcare professionals who have concerns about seeing and treating patients) early on during the pandemic about the consequences of ignoring other acute medical problems such as ACS, provide various measures for them to reach hospital early and give reassurance with the best practices adopted in hospitals to avoid contracting the virus from the hospital environment.

\section{References}

1. WHO Director-General's opening remarks at the media briefing on COVID-19- 11 March 2020. https://www.who.int/dg/speeches/detail/ who-director-general-s-opening-remarks-at-the-media-briefing-oncovid-19-11-march-2020 (last accessed on 10 Sept 2020).

2. Hendren NS, Drazner MH, Bozkurt B, Cooper Jr LT. Description and proposed management of the acute COVID-19 cardiovascular syndrome. Circulation 2020;141(23):1903-1914. DOI: 10.1161/ CIRCULATIONAHA.120.047349.

3. Mahmud E, Dauerman HL, Welt FGP, Messenger JC, Rao SV, Grines $C$, et al. Management of acute myocardial infarction during the COVID-19 pandemic: a consensus statement from the Society for Cardiovascular Angiography and Interventions (SCAI), the American College of Cardiology (ACC), and the American College of Emergency Physicians (ACEP). Catheter Cardiovasc Interv 2020;96(2):336-345. DOI: $10.1002 / \mathrm{ccd} .28946$. Online ahead of print.

4. Kerkar PG, Naik N, Alexander T, Bahl VK, Chakraborty RN, Chatterjee SS, et al. Cardiological society of india: document on acute MI care during COVID-19. Indian Heart J 2020;72(2):70-74. DOI: 10.1016/j. ihj.2020.04.009.

5. Braiteh N, Rehman W, Md Alom, Skovira V, Breiteh N, Rehman I, et al. Decrease in acute coronary syndrome presentations during the
COVID-19 pandemic in upstate new york. Am Heart J 2020;226:147151. DOI: $10.1016 /$ j.ahj.2020.05.009.

6. Metzler B, Siostrzonek P, Binder RK, Bauer A, Reinstadler SJ. Decline of acute coronary syndrome admissions in Austria since the outbreak of COVID-19: the pandemic response causes cardiac collateral damage. Eur Heart J 2020. ehaa314. DOI: 10.1093/eurheartj/ehaa314.

7. Rodriguez-Leor O, Cid-Álvarez B, Ojeda S, Martín-Moreiras J, Rumoroso JR, López-Palop R, et al. Impact of the COVID-19 pandemic on care activity in interventional cardiology in Spain. REC Interv Cardiol 2020;2:82-89.

8. Secco GG, Zocchi C, Parisi R, Roveta A, Mirabella F, Vercellino M, et al. decrease and delay in hospitalization for acute coronary syndromes during the 2020 SARS-CoV-2 pandemic. Can J Cardiol 2020;36(7):1152-1155. DOI: 10.1016/j.cjca.2020.05.023 [Epub ahead of print].

9. Rattka M, Baumhardt M, Dreyhaupt J, Rothenbacher D, Thiessen K, Markovic S, et al. 31 Days of COVID-19-cardiac events during restriction of public life-a comparative study. Clin Res Cardiol 2020. 1-7. DOI: 10.1007/s00392-020-01681-2.

10. Tsioufis K, Chrysohoou C, Kariori M, Leontsinis I, Dalakouras I, Papanikolaou A, et al. The mystery of "missing" visits in an emergency cardiology department, in the era of COVID-19.; a time-series analysis in a tertiary Greek general hospital. Clin Res Cardiol 2020. 1-7. DOI: 10.1007/s00392-020-01682-1.

11. Rosa SD, Spaccarotella C, Basso C, Calabrò MP, Curcio A, Filardi PP, et al. Società Italiana di cardiologia and the CCU academy investigators group. Reduction of hospitalizations for myocardial infarction in Italy in the COVID-19 era. Eur Heart J 2020;41(22):2083-2088. DOI: 10.1093/ eurheartj/ehaa409.

12. De Filippo O, D'Ascenzo F, Angelini F, Bocchino PP, Conrotta F, Saglietto A, et al. Reduced rate of hospital admissions for ACS during COVID-19 outbreak in northern Italy. N Engl J Med 2020;383(1):88-89. DOI: 10.1056/NEJMc2009166.

13. Tam CF, Cheung KS, Lam S, Wong A, Yung A, Sze M, et al. Impact of coronavirus disease 2019 (COVID-19) outbreak on ST-segmentelevation myocardial infarction care in Hong Kong, China. Circ Cardiovasc Qual Outcomes 2020;13(5):e006631. DOI: 10.1161/ CIRCOUTCOMES.120.006631.

14. Garcia S, Albaghdadi MS, Meraj PM, Schmidt C, Garberich R, Jaffer FA, et al. Reduction in ST-segment elevation cardiac catheterization laboratory activations in the United States during COVID-19 pandemic. J Am Coll Cardiol 2020;75(22):2871-2872. DOI: 10.1016/ j.jacc.2020.04.011. Epub 2020 Apr 10.

15. Ashraf $S$, llyas $S$, Alraies MC. Acute coronary syndrome in the time of the COVID-19 pandemic. Eur Heart J 2020;41(22):2089-2091. DOI: 10.1093/eurheartj/ehaa454. 